\title{
ACESSO AO ABORTO E LIBERDADES LAICAS
}

\author{
Roberto Arriada Lorea* \\ Universidade Federal do Rio Grande do Sul - Brasil
}

Resumo: Enfrentar o tema do aborto no Brasil requer uma perspectiva laica, na medida em que a liberdade de consciência assegurada na Constituição Federal impõe ao Estado contemplar não apenas as diferentes visões oriundas de distintas religiões, mas, principalmente, assegurar o direito à diversidade existente no seio de uma mesma religião, garantindo o direito de divergir da hierarquia de sua própria igreja. Assim, não havendo obstáculo jurídico à descriminalização do aborto no país, resta aos legisladores reformar a lei vigente, para descriminalizar o aborto, atendendo os compromissos assumidos pelo Brasil perante organismos internacionais de proteção dos direitos humanos e assegurando a eficácia das liberdades laicas.

Palavras-chave: aborto, direito, liberdades laicas, religião.

Abstract: In Brazil, face an issue like abortion requires a lay perspective considering that the freedom of conscience assured by the Federal Constitution lays upon the State the need to look not only at different views from different religions but specially assure the right to the existing diversity within the same religion, as well as, the right to diverge from the hierarchy of his/her own religion. Therefore there is no legal barrier for the decriminalization of abortion in the country. It is up to the legislators to reform the present law to decriminalize abortion, assuming the commitments made by Brazil upon international organizations for the protection of the human rights assuring the efficacy of lay liberties.

Keywords: abortion, law, lay liberties, religion.

* Pesquisador associado ao Núcleo de Pesquisa em Antropologia do Corpo e da Saúde (Nupacs).

Horizontes Antropológicos, Porto Alegre, ano 12, n. 26, p. 185-201, jul./dez. 2006 


\section{Introduç̃o}

Quando o Congresso Nacional legalizou o divórcio em 1977, o Estado brasileiro deu um gigantesco passo no sentido de assegurar as liberdades laicas no país. Só então as pessoas casadas passaram a receber tratamento igualitário por parte do Estado brasileiro, independentemente de sua (não) crença religiosa.

Convém salientar que ao assegurar as liberdades laicas, o Estado não se limita apenas a assegurar a co-existência pacífica entre diferentes credos. Ainda mais importante que garantir a liberdade de crença, é o fato de que a laicidade garante o direito de divergir da hierarquia de sua própria igreja, contemplando a diversidade existente no seio de uma mesma doutrina religiosa.

Essa é a razão pela qual, no Brasil, um casal católico pode se divorciar sem que seja permitido ao juiz de direito negar o divórcio com base em sua própria convicção religiosa ou sob o argumento de que a hierarquia da religião católica não admite o divórcio e que um casal católico não pode infringir um dogma de sua própria igreja.

Não é meu objetivo debater aqui as razões históricas que tanto retardaram a aprovação legislativa dessa importante conquista democrática no território brasileiro. Limito-me a referir que os legisladores da época não estiveram imunes a pressões de ordem religiosa, repetindo-se o que ocorrera quando se tentou secularizar o casamento no Brasil, na segunda metade do século XIX (Lordello, 2002).

O objetivo deste artigo é contribuir para o debate atual sobre a reforma da legislação que ainda criminaliza o aborto no país. Para tanto importa destacar que, ao contrário do que possa parecer, a questão da religião deve ser contemplada no debate justamente para assegurar a liberdade religiosa, atendendo a amplos setores da sociedade brasileira que, embora comungando os valores da religião católica, divergem da orientação da hierarquia de sua própria igreja quanto ao enfrentamento da questão do aborto.

Nesse sentido, para que se possa aprofundar a questão, será necessário apresentar alguns dados que são reveladores do pensamento da população católica brasileira acerca de questões diretamente ligadas à saúde sexual e reprodutiva das mulheres.

Assim ficará mais compreensível a divergência entre a orientação que parte da hierarquia católica e os valores defendidos por uma significativa parcela dos fiéis. 
Dada essa importante divergência, resta ao estado democrático de direito se manter eqüidistante de quaisquer posições religiosas, assegurando a possibilidade de convívio pacífico entre idéias conflitantes. É dever do Estado implementar políticas públicas capazes de atender ao interesse público, assegurando que todas as pessoas recebam tratamento igualitário por parte do Estado, independentemente de sua (não) crença religiosa.

Por fim, numa perspectiva estritamente jurídica, procurarei demonstrar que não há qualquer obstáculo de ordem jurídica à descriminalização do aborto no país, bastando que se desconstrua o mito da proteção jurídica da vida desde a concepção.

\section{Religião}

A liberdade religiosa assegurada na Constituição Federal de $1988^{1}$ estabelece a obrigatoriedade de tratamento igualitário, por parte do Estado brasileiro, a todas as formas de pensamento religioso, o que é suficiente para determinar que as políticas públicas, necessariamente, contemplem a diversidade de pensamento, independentemente da existência de uma religião predominante no cenário nacional.

O aspecto que gostaria de ressaltar, porque me parece menos visível, é a liberdade religiosa assegurada pela laicidade àqueles que, sem se afastar de sua crença religiosa, divergem da postura adotada pela hierarquia de sua própria igreja.

Ponto fundamental para a compreensão da defesa de uma postura laica acerca do tema do aborto no Brasil, é entender que a posição da religião católica sobre a questão não se confunde com a posição adotada pela hierarquia dessa mesma igreja. Mais precisamente, importa registrar que não há consenso acerca do tema, podendo-se referir importantes vozes católicas que admitem a possibilidade de a mulher exercitar sua liberdade de consciência frente ao dilema de interromper uma gravidez indesejada. Nesse sentido, ver Leonardo Boff (2006, p. 20), Maria Rosado-Nunes (2006, p. 26), Frances Kissling (2001, p. 14) e Beverly Harrison (2006).

\footnotetext{
${ }^{1}$ Especialmente através do artigo 5o, incisos V, VI e VII, e artigo 19, inciso I.
} 
Pensar que a existência de correntes de pensamento divergente não tem maior relevância, em face da hegemonia da hierarquia da Igreja relativamente às questões ligadas aos direitos sexuais seria incorrer em uma simplificação equivocada. Como se verá adiante, mesmo uma organização não governamental cuja postura, aparentemente, é contrária aos dogmas da Igreja católica, como é o caso das Católicas pelo Direito de Decidir, pode estar mais harmonizada com o pensamento da população católica brasileira do que a hierarquia dessa igreja.

Isso é o que demonstra a pesquisa realizada pelo Ibope $^{2}$ no Brasil em 2005, a qual aponta para uma expressiva divergência entre o pensamento da população católica e o discurso da hierarquia da Igreja. Tratou-se de uma pesquisa realizada pela ONG Católicas pelo Direito de Decidir, justamente para investigar qual o pensamento dos católicos brasileiros acerca de temas ligados à sexualidade, especialmente os direitos reprodutivos.

Dentre outros dados, merece destaque o fato de que $78 \%$ dos católicos (contra 74\% da população em geral) são favoráveis à oferta de aborto legal nos serviços públicos de saúde. Impressiona também o fato de que $86 \%$ da população católica pesquisada afirma que uma mulher pode utilizar métodos anticoncepcionais e continuar sendo uma boa católica.

Em alguns aspectos, os resultados da pesquisa sugerem, mais que uma simples divergência, um verdadeiro antagonismo de posições, como é o caso da aprovação do uso de preservativo por 92\% dos católicos brasileiros.

Tão significativa quanto a divergência de posições entre os fiéis e a hierarquia católica, é a compreensão de $85 \%$ dos católicos de que o presidente da República deve governar segundo a diversidade de opiniões existentes no país e não com base nos ensinamentos da igreja católica. Nessa mesma linha, 86\% da população católica entrevistada acredita que legisladores e juízes devem tomar suas decisões baseados na diversidade de opiniões existentes e não com base nos ensinamentos da Igreja católica.

Partindo-se desses dados, pode-se melhor examinar a questão da falta de legitimidade do discurso de uma hierarquia religiosa que pretende atuar no plano político como se estivesse representando a população católica que vive no

2 A metodologia e os resultados da pesquisa estão disponíveis no site da ONG Católicas pelo Direito de Decidir (CDD), em <http://www.catolicasonline.org.br/outros/EstadoLaico.pdf>.

Horizontes Antropológicos, Porto Alegre, ano 12, n. 26, p. 185-201, jul./dez. 2006 
Brasil. Seja porque a hierarquia católica sustenta posições que não refletem sequer a maioria da população católica, seja porque não tem qualquer papel representativo no plano político, uma vez que os católicos brasileiros se fazem representar através do exercício de seus direitos políticos, elegendo seus representantes por ocasião das eleições, percebe-se o equívoco de um discurso ainda alimentado por alguns setores conservadores da Igreja.

De resto, para finalizar essa breve incursão na esfera religiosa do tema, cabe citar Daniele Hervieu-Léger (1997, p. 362-364, tradução minha), quando a mesma refere que

as instituições religiosas não podem mais pretender reger as sociedades. Suas atividades não se exercem legitimamente senão no interior de um campo religioso especializado e não têm abrangência para além de um grupo determinado de crentes voluntários. O sentimento religioso se torna, quando subsiste, um assunto individual. A crença religiosa perde seu papel determinante na formação da identidade individual e coletiva.

No mesmo sentido, remetendo a questão religiosa para o plano individual, destaca Roberto Blancarte (2004, p. 175, tradução minha):

O assunto é relativamente simples: há quem diga que tem "a verdade” e que todos devem acatar a mesma. Por outro lado, estão aqueles que assumem que podem haver distintas verdades, ou maneiras de chegar a ela, e que a única maneira de resolver o problema de maneira civilizada é mediante um sistema democrático, que se rege pelo princípio da maioria, expressada nas urnas, deixando para a consciência individual a relação de cada um com Deus.

Enfim, sem a pretensão de esgotar o tema, cabe-me aqui apresentar as razões pelas quais a análise do aspecto religioso na questão de assegurar o acesso ao aborto não pode se limitar a uma simplificação que contrapõe católicos e não-católicos, dado que os benefícios de um Estado laico alcançam a todos indistintamente.

\section{Direito}

Quando o debate sobre o direito ao aborto ganha espaço na agenda política brasileira, aqueles que são contrários à proteção integral dos direitos huma- 
nos das mulheres invocam o mito de que a Constituição Federal de 1988 protege o direito à vida desde a concepção, tornando inviável qualquer tentativa de descriminalizar o aborto no território brasileiro.

O enfrentamento da questão do aborto no estado democrático de direito não pode se dar à revelia de importantes decisões internacionais sobre o tema. Entretanto, essa prática tem sido recorrente entre alguns juristas que têm se dedicado ao tema, o que empobrece o nível do debate sobre o direito ao aborto no Brasil.

Não se trata aqui de sustentar uma posição contrária ou favorável ao aborto, na medida em que essa questão transcende os limites do campo jurídico, podendo, conforme o caso, alcançar motivação religiosa (de ordem individual, portanto) que, como visto acima, pode contemplar, ou não, a possibilidade de interrupção voluntária da gravidez.

Para pensar sobre o direito ao aborto, necessariamente devemos nos ater a argumentos de ordem pública, válidos no mundo jurídico. Para tanto é preciso incorporar o conteúdo de conferências internacionais ${ }^{3}$ e decisões de organismos internacionais de solução de conflitos que, não obstante a sua relevância para o direito brasileiro, têm sido ignoradas por significativa parcela de nossos juristas.

Quando se trata de enfrentar o tema do aborto à luz do direito, é importante nos distanciarmos de concepções sedimentadas no senso comum. Mesmo que o senso comum esteja reproduzido no discurso de personalidades renomadas na cena jurídica nacional, como veremos adiante.

Dados os limites deste trabalho, não vou me deter no enfrentamento da questão do dilema moral atinente ao aborto. Sobre esse ponto reporto-me a autores como Hart (1987), Thomsom (1998) e Dworkin (2003). ${ }^{4}$ Também não me aprofundarei no exame do tema sob a perspectiva da justiça social, limitando-me

\footnotetext{
3 Refiro-me especialmente a duas conferências da Organização das Nações Unidas: a Conferência Mundial Sobre População e Desenvolvimento, realizada no Cairo em 1994, na qual o Estado brasileiro se comprometeu a assegurar às mulheres o controle sobre a sua fecundidade, reconhecendo o aborto como uma grave questão de saúde pública (parágrafo 8.25), e a IV Conferência Mundial da Mulher, realizada em Pequim em 1995, na qual o Estado brasileiro se comprometeu a assegurar o direito ao sexo sem fim reprodutivo e rever a sua legislação punitiva às mulheres que se submetem ao aborto (parágrafo 106k). Sobre o tema, vide Ventura (2002).

4 Para referências na área da ética biomédica vide Cook (2004); antropologia, Leal e Lewgoy (1998); impacto da gravidez não desejada na saúde da mulher, Araújo et al. (2005); reprodução e sexualidade, Buglione (2002); direitos sexuais e direitos reprodutivos, Corrêa e Pechesky (1996); norma técnica que acabou com a exigência de boletim de ocorrência policial para realização de aborto legal nas hipóteses de gravidez resultante de violência sexual, Lorea (2005).
}

Horizontes Antropológicos, Porto Alegre, ano 12, n. 26, p. 185-201, jul./dez. 2006 
a referir que, no Brasil, os agentes políticos do Estado, sejam governantes, legisladores ou magistrados, assim como os membros do Ministério Público, na hipótese de uma gravidez indesejada, podem fazer a opção por um aborto seguro. ${ }^{5}$

Para que possamos compreender a questão do direito ao aborto e enfrentá-la juridicamente, é importante compreender, como afirma Dworkin (2003, p. 42), que

a maioria das pessoas supõe que a grande polêmica sobre o aborto é, no fundo, um debate sobre uma questão moral e metafísica: saber se mesmo um embrião recém-fertilizado já é uma criatura humana com direitos e interesses próprios, [...] a despeito de sua grande popularidade, esse modo de apresentar o debate é fatalmente enganoso.

No mesmo sentido, salienta Dwyer (1998, p. 128, grifo do autor):

Pode-se discordar a respeito de se um feto é ou não uma pessoa de muitas maneiras. No entanto, mesmo que pudéssemos concordar com respeito à questão metafísica de quais são as condições necessárias e suficientes para ser uma pessoa, e pudéssemos concordar sobre a questão factual acerca do feto satisfazer ou não essas condições, nós ainda assim não poderíamos concluir que o aborto é aceitável ou inaceitável moralmente.

Note-se que nenhum dos dois argumentos abaixo é válido: A. um feto é uma pessoa a partir do momento da concepção. Portanto, o aborto é sempre moralmente inaceitável. B. Um feto não é uma pessoa em qualquer estágio do seu desenvolvimento. Portanto, o aborto é sempre moralmente aceitável.

Seguindo nessa linha de raciocínio, é preciso compreender que o debate jurídico sobre a questão não se limita à definição quanto ao feto ser ou não uma pessoa. O direito à vida não é absoluto, bastando que se diga que nosso ordenamento jurídico admite que se mate alguém até mesmo em legítima defesa da propriedade. Direito à propriedade que está assegurado no caput do artigo 5ơ da Constituição Federal, justamente ao lado do direito à vida.

\footnotetext{
Esse verdadeiro privilégio (liberdade de interromper a gravidez sem colocar a própria vida em risco) não está acessível à maioria da população brasileira. Assim, no Brasil, quem precisa da reforma da legislação punitiva ao aborto não tem o poder de realizá-la, enquanto aqueles que detêm esse poder não precisam modificar a legislação para ter acesso a um aborto seguro.
}

Horizontes Antropológicos, Porto Alegre, ano 12, n. 26, p. 185-201, jul./dez. 2006 
Para os fins deste trabalho, cuja pretensão é oferecer uma abordagem estritamente jurídica do tema do aborto, buscarei focar a atenção na orientação jurisprudencial sobre a questão. ${ }^{6}$ Isso porque acredito que essa tarefa ainda não recebeu a merecida atenção de parte dos nossos operadores do direito, o que parece comprometer a capacidade de alguns juristas enfrentarem, com profundidade, o tema do aborto.

Alguns juristas (Chemeris, 2005; Moreira, 2004), que escrevem sobre o aborto no Brasil, têm suas análises sobre o tema empobrecidas justamente por não contemplarem decisões internacionais sobre essa questão. Isso faz com que suas reflexões se revelem juridicamente superficiais. Essa superficialidade adquire maior visibilidade quando se vê referências ao Pacto de São José da Costa Rica, ${ }^{7}$ omitindo-se a existência da Resolução 23/81, da Comissão Interamericana de Direitos Humanos.

Essa ocorrência específica, que se pode constatar na produção intelectual de alguns juristas (Fonteles, 2004; Martins, 2003), visa difundir a idéia de que o fato de o Brasil ser signatário do Pacto de São José, por si só, obstaculiza a descriminalização do aborto no Brasil. Em outras palavras, seria inútil o debate sobre o tema do direito ao aborto instalado no país porque, ao final, o Supremo Tribunal Federal reconheceria a inconstitucionalidade de uma lei que viesse a descriminalizar a prática do aborto consentido.

É importante perceber que esses mesmos juristas, que à legislação descriminante sobrepõem uma jurisprudência hipotética, não demonstram o mesmo apego à jurisprudência quando se trata de casos concretos. Tanto é assim que sequer mencionam em seus escritos a jurisprudência internacional já existente sobre o tema.

\footnotetext{
6 Registro que me concentrarei no plano internacional. Para exame da jurisprudência pátria, sem prejuízo de decisões já prolatadas nos estados de Goiás, Pernambuco, Rio de Janeiro, Minas Gerais e Rondônia, destaco duas decisões do Rio Grande do Sul: acórdão prolatado no processo $\mathrm{n}^{0}$ 70011918026, TJRS, relatora desembargadora Elba Bastos, julgado em 09-06-2005; sentença do juiz Rafael Pagnon Cunha, prolatada na Comarca de Tupanciretã (RS), em 11-05-2005 (Cunha, 2005). No âmbito dos tribunais superiores, reporto-me à decisão monocrática do STF, da lavra do ministro Marco Aurélio, proferida na medida cautelar de descumprimento de preceito fundamental, MCDPF no 54-8, prolatada em $1^{\circ}$-07-2004; e a liminar deferida pelo presidente do STJ, ministro Edson Vidigal, no habeas corpus nํㅜ 84025, em 22-12-2005.

7 Como é conhecida a Convenção Americana de Direitos Humanos, adotada em São José da Costa Rica, em 22 de novembro de 1969 e ratificada pelo Brasil em 1992, através do Decreto 678, de 6 de novembro de 1992.
} 
O certo é que, se aprofundassem sua análise, chegariam à Resolução 23/ 81, da Corte Interamericana de Direitos Humanos, decisão proferida por ocasião do caso 2141, mundialmente conhecido como caso Baby Boy. Como se verá adiante, tal é a relevância do conteúdo da jurisprudência internacional ${ }^{8}$ para o enfrentamento jurídico do aborto no Brasil, que se mostra inviável uma abordagem jurídica do tema que não a incorpore na reflexão.

Contudo, a existência de análises juridicamente superficiais, como já referido, parece contribuir para a proliferação de uma errônea linha de interpretação da Constituição Federal e textos internacionais. Segundo essa corrente de pensamento, no ordenamento jurídico brasileiro o aborto seria juridicamente inadmissível em face da proteção jurídica da vida desde a concepção.

Tais autores, conseqüentemente, prestam limitada - ou nenhuma - colaboração ao operador do direito que esteja em busca de elementos de convicção consistentes para o enfrentamento jurídico de tão relevante questão, como é o da descriminalização do aborto no Brasil.

Procurando elevar o nível do debate jurídico sobre o tema, tratarei nas páginas seguintes de dois dispositivos legais que têm sido mencionados como pilares da inviabilidade jurídica da descriminalização do aborto no Brasil.

O primeiro é o artigo 5o, da Constituição Federal, que estabelece que "todos são iguais perante a lei, sem distinção de qualquer natureza, garantindose aos brasileiros e aos estrangeiros residentes no País a inviolabilidade do direito à vida, à liberdade, à igualdade, à segurança e à propriedade, nos termos seguintes [...]”.

Vê-se que o direito à vida aí preconizado está assegurado aos brasileiros e aos estrangeiros residentes no Brasil. Essa referência àquelas pessoas às quais se destina a proteção elencada no dispositivo, aliada à redação dada ao artigo, que não traz qualquer referência expressa à proteção da vida desde a

8 A relevância da jurisprudência internacional, para uma adequada análise do direito ao aborto no Brasil, fica patente quando se percebe, por exemplo, que a questão do aborto (antecipação de parto) nos casos de má-formação fetal incompatível com a vida pende de decisão no Supremo Tribunal Federal, enquanto, no plano internacional, o Comitê de Direitos Humanos das Nações Unidas (Comunicación no 1153/2003, em 17-11-2005 - Karen Huamán vs. Peru) condenou o Estado do Peru a indenizar uma mulher pelo fato de a mesma não ter tido acesso a um aborto seguro quando desejava interromper a gravidez em função de má-formação fetal incompatível com a vida. Necessariamente essa decisão deve ser tomada em conta pelos ministros do STF, na medida em que o Brasil é signatário do Pacto dos Direitos Civis e Políticos, cujo texto serviu de base à decisão.

Horizontes Antropológicos, Porto Alegre, ano 12, n. 26, p. 185-201, jul./dez. 2006 
concepção, é evidência de que o texto constitucional não recepcionou a doutrina da defesa da vida desde a concepção.

Tanto é assim, que a proposta no sentido de que a Constituição Federal referisse expressamente a proteção da vida desde a concepção, formulada à época da constituinte pelo então deputado Meira Filho, viu-se rejeitada pela Assembléia Nacional Constituinte. ${ }^{9}$

Portanto, é possível afirmar com segurança que a Constituição Federal vigente no Brasil não recepcionou a doutrina da proteção da vida desde a concepção, posto que deixou de fazê-lo expressamente, como seria necessário para que assim fosse interpretada, a exemplo do que ocorre em outros países. ${ }^{10}$ É dizer, os legisladores constituintes enfrentaram o tema e decidiram não adotar um texto constitucional que contemplasse a proteção jurídica da vida desde a concepção.

Para suprir a ausência da proteção constitucional da vida desde a concepção, há quem argumente (Fonteles, 2004) que o artigo 4º, inciso I, do Pacto de São José da Costa Rica, protege a vida desde a concepção, o que determinaria que o direito ao aborto no Brasil fosse inconstitucional.

Alguns operadores do direito no Brasil (Bicudo, [s.d.]; Martins, 2003), aprofundando-se no equívoco, sustentam que mesmo as hipóteses de abortamento legal já previstas no Código Penal de 1940 hoje seriam inconstitucionais, em face da proteção da vida desde a concepção assegurada nesse pacto, que tem força de texto constitucional no Brasil.

Esse equívoco é impressionante na medida em que foi o Pacto de São José da Costa Rica (1969), na sua origem, que se curvou aos Códigos Penais já vigentes na época, dentre os quais o brasileiro (1940), que já admitiam o direito ao aborto em algumas hipóteses. Portanto, afirmar que o artigo 128 do Código Penal brasileiro é inconstitucional porque afronta o artigo 5 da Constituição Federal (1988) ou o 4ํ, inciso I, do Pacto de São José, mais que um equívoco, é um erro grosseiro.

\footnotetext{
9 Ver Diário da Assembléia Nacional Constituinte (Brasil, 1987/88, p. 7419-7422, 7450).

${ }^{10}$ Ver, por exemplo, o artigo 19, da Constituição do Chile: "La Constitución asegura a todas las personas: 1 . El derecho a la vida y a la integridad física y psíquica de la persona. La ley protege la vida del que está por nacer.” Do mesmo modo, referindo-se expressamente à proteção da vida do feto, o artigo 4º da Constituição do Peru: "El derecho a la vida es inherente a la persona humana. Se garantiza su protección, en general, desde la concepción.”
}

Horizontes Antropológicos, Porto Alegre, ano 12, n. 26, p. 185-201, jul./dez. 2006 
Tanto mais grave é o erro, se considerarmos que o artigo 226, § 7으, da Constituição Federal assegura que o planejamento familiar é livre decisão do casal, competindo ao Estado propiciar recursos para o exercício desse direito. A gravidez decorrente de estupro, à evidência, viola o direito da mulher ao livre exercício do planejamento familiar, razão, por si só, suficiente para que lhe seja assegurado o direito ao aborto.

Ainda, cabe destacar que esse mesmo direito está assegurado e ampliado no parágrafo 7.3 da Conferência Mundial sobre População e Desenvolvimento, da Organização das Nações Unidas, realizada no Cairo, em 1994, que conceitua o que sejam os direitos reprodutivos, nos seguintes termos: "Direito básico de todo casal e de todo indivíduo de decidir livre e responsavelmente sobre o número, o espaçamento e a oportunidade de ter filhos e de ter a informação e os meios de assim o fazer, e o direito de gozar do mais elevado padrão de saúde sexual e reprodutiva."

Vê-se, então, que, sob qualquer ângulo que se examine a questão, revelase inexistente a proteção jurídica da vida desde a concepção. Para tanto, não aproveita recorrer ao artigo 2ํㅡㄹ Código Civil de 2002.

É oportuno referir a existência de corrente de pensamento que preconiza estar assegurado o direito à proteção jurídica da vida desde a concepção no artigo 2ํㅡㄹ do Código Civil, que estabelece: “A personalidade civil da pessoa começa com o nascimento com vida; mas a lei põe a salvo, desde a concepção, os direitos do nascituro.” Há quem sustente que seria incongruente que a lei ordinária protegesse o direito à herança, do nascituro, mas não lhe assegurasse a proteção da vida.

Resumidamente, pode-se rebater esse argumento afirmando que o que não seria lógico é o legislador constituinte pretender a proteção da vida desde a concepção e deixar para fazê-lo na legislação ordinária, sem que houvesse tal proteção assegurada na Constituição Federal, a qual, como se vê no presente trabalho, contém dispositivos que asseguram os direitos reprodutivos.

De resto, como já supramencionado, a Assembléia Nacional Constituinte de 1988 teve oportunidade de aprovar um texto que fizesse a referência expressa à proteção do direito à vida desde a concepção, optando por não fazê-lo.

O segundo dispositivo legal que precisa ser melhor examinado por nossos operadores do direito está contido no Pacto de São José, sobre o qual vou agora focar a minha análise, dada a sua relevância para o tema da descriminalização do aborto no Brasil, à luz da jurisprudência internacional, com reflexos diretos também para outros países da América Latina. 
O Pacto de São José, em seu artigo $4^{\circ}$, inciso I, estabelece que "toda persona tiene derecho que se respete su vida. Este derecho estará protegido por la ley y, en general, a partir del momento de la concepción. Nadie puede ser privado de la vida arbitrariamente”.

Sustentar que esse dispositivo impede que os Estados signatários do pacto descriminalizem o aborto revela enorme desconhecimento sobre a construção histórica do Pacto de São José da Costa Rica, ou, pior ainda, resvala para a esfera da desonestidade intelectual.

Isso porque o órgão competente para interpretar o Pacto de São José é a Comissão Interamericana de Direitos Humanos (CIDH), a qual, ao apreciar o caso 2141, em que figurava como demandado os Estados Unidos da América, decidiu, através da Resolução 23/81, de 6 de março de 1981, que o direito ao

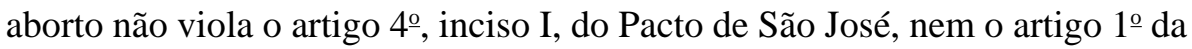
Declaração Americana dos Direitos do Homem.

Com o objetivo de contribuir para o debate sobre o direito ao aborto, na perspectiva dos direitos humanos, procurarei destacar - praticamente transcrevendo-os ${ }^{11}$ - os principais fundamentos da decisão da CIDH. Primeiramente, cabe registrar que a CIDH é o organismo da Organização dos Estados Americanos (OEA), responsável pela observância e respeito aos direitos humanos.

Podemos situar o início da construção do Pacto de São José, na Conferência Interamericana sobre Problemas da Guerra e da Paz, realizada no México, em 1945, cuja resolução XL determinou que o Comitê Jurídico Interamericano, sediado no Rio de Janeiro, formulasse um projeto de uma Declaração Internacional dos Direitos e Deveres do Homem.

Na Conferência Internacional dos Estados Americanos, realizada em 1948, na cidade de Bogotá, debateu-se o texto, cuja redação original, em seu artigo $1^{1}$, tratando do direito à vida, estabelecia que "toda persona tiene derecho a la vida. Este derecho se extiende al derecho a la vida desde el momento de la concepción.”

${ }^{11}$ Cumpre registrar que o texto da Resolução 23/81, em espanhol, contém notas de rodapé que apontam as Actas y Documentos onde se encontram consignadas as discussões e posições adotadas pelas delegações. 
Ao final dos trabalhos, o texto foi modificado, ficando com a seguinte redação: "Todo ser humano tiene derecho a la vida, libertad, seguridad, o integridad de su persona."

Essa modificação ocorreu para que se harmonizasse o texto da Conferência de Bogotá às legislações nacionais dos Estados, as quais admitiam basicamente cinco tipos de abortamento legal: a) para salvar a vida da mãe; b) na gravidez decorrente de estupro; c) para proteger a honra da mulher honrada; d) prevenir a transmissão de doença hereditária ou contagiosa; e e) por razões econômicas.

A mudança no texto, retirando-se a referência à proteção da vida desde a concepção, harmonizou-se com as legislações então vigentes, que admitiam o aborto em uma ou mais das hipóteses referidas, nos seguintes países: Argentina, Brasil, Costa Rica, Cuba, Equador, Estados Unidos, México, Nicarágua, Paraguai, Peru, Porto Rico, Uruguai e Venezuela.

Assim, fica claro que a Conferência de Bogotá, de 1948, enfrentou a questão da proteção da vida desde a concepção e decidiu não adotar uma redação que contemplasse essa proteção, justamente para não restringir o direito ao aborto então existente nas legislações nacionais dos Estados signatários da Declaração Americana dos Direitos e Deveres Fundamentais do Homem.

Em 1968, quando da preparação da Conferência de São José da Costa Rica, onde seria debatido e votado o texto da Convenção Americana de Direitos Humanos, novamente houve a tentativa de aprovar um texto que contemplasse a proteção da vida desde a concepção.

Nessa oportunidade o projeto previa o direito à vida, voltando a introduzir o conceito de proteção do feto: "Este derecho estará protegido por la ley desde el momento de la concepción.”

Todavia, ainda antes de ir a votação, o projeto de convenção foi submetido à Comissão Interamericana de Direitos Humanos e ao Conselho da Organização dos Estados Americanos. Nos debates que se seguiram, especialmente em continuidade ao que fora já debatido na Conferência de Bogotá, decidiu-se apresentar a seguinte proposta de redação: “Este derecho estará protegido por la ley y, en general, desde el momento de la concepción.”

Durante a Conferência de São José, a delegação do Brasil apresentou emenda propondo a eliminação da frase final do parágrafo, para que fosse suprimida qualquer referência à proteção do feto. A delegação dos Estados Unidos apoiou a proposta brasileira, enquanto a delegação da República Dominicana apresentou proposta em separado, com o mesmo objetivo. Em 
sentido contrário, a delegação do Equador propôs que se retirasse a expressão "en general".

O texto finalmente aprovado manteve o compromisso adotado na Conferência de Bogotá, harmonizando-se com as legislações nacionais que contemplavam o direito ao aborto. Assim, o texto aprovado em São José deixou de assegurar a proteção da vida desde a concepção como regra absoluta, justamente para não conflitar com as legislações nacionais que garantiam o direito ao aborto.

Essa é a fundamentação que, constituindo-se em uma profunda análise da construção histórica do Pacto de São José, por ocasião do exame do caso 2141, firmou o entendimento da Comissão Interamericana de Direitos Humanos no sentido de que o direito ao aborto não viola o artigo 1ํㅡㄹ da Declaração Americana de Direitos do Homem, nem o artigo 4ㅜ, inciso I, do Pacto de São José da Costa Rica.

O fato de que Estados Unidos não seja signatário do Pacto de São José da Costa Rica, como explicitado na decisão examinada, em nada altera a interpretação dada ao caso 2141, originário de um conflito no território norte-americano, cuja solução repercute não apenas no Brasil, mas em todas as Américas.

Portanto - ao contrário do mito que é largamente difundido em nosso país - não há qualquer obstáculo de ordem jurídica à aprovação da reforma legal para descriminalizar o aborto no Brasil. Ao contrário, trata-se de alteração legislativa necessária para que seja assegurada a proteção integral dos direitos humanos das mulheres, compromisso assumido pelo Estado brasileiro nas Conferências da ONU realizadas no Cairo, em 1994, e em Pequim, em 1995.

\section{Conclusão}

Do exposto, retomando o argumento inicial, tenho que não há alternativa outra à garantia das liberdades laicas no contexto de um estado democrático de direito que não seja atender à pluralidade de pensamentos que convivem na sociedade brasileira.

Nesse sentido, ao reformar a legislação atual para descriminalizar o aborto no país, os legisladores estariam assegurando a diversidade, contemplando a possibilidade de que nenhuma posição se sobreponha às demais, com isso fomentando o debate civilizado e respeitando a decisão de cada um na esfera individual. 
Afastada a questão religiosa, sobressai o critério jurídico, cuja perspectiva, como tivemos a oportunidade de ver, e como sobram exemplos nas democracias modernas, afasta a possibilidade de que se imponha a uma nação qualquer espécie de pensamento único.

\section{Referências}

ARAÚJO, Maria José de Oliveira et al. O impacto da gravidez não desejada na saúde da mulher. In: PITANGUY, Jacqueline; MOTA, Adriana. Os novos desafios da responsabilidade política. Rio de Janeiro: Cepia, 2005. cap. 4, p. 101-138.

BICUDO, Hélio. O aborto legal não existe. [s.d.]. Disponível em: <http:// www.neofito.com.br/artigos/art01/const7.htm>. Acesso em: 9 fev. 2006.

BLANCARTE, Roberto. Entre la fe y el poder: política y religión en México. Grijalbo: México, 2004.

BOFF, Leonardo. Em defesa da vida: aborto e direitos humanos. In: CAVALCANTI, Alcilene; XAVIER, Dulce (Org.). São Paulo: Católicas pelo Direito de Decidir, 2006. p. 17-21.

BRASIL. Assembléia Nacional Constituinte. Diário da Assembléia Nacional Constituinte (Diário da ANC). Brasília, 1987/88. Diversos números.

BUGLIONE, Samantha (Org.). Reprodução e sexualidade: uma questão de justiça. Porto Alegre: Themis:Safe, 2002.

COMISIÓN INTERAMERICANA DE DERECHOS HUMANOS. Resolución n. 23/81: caso n. 2141. 1981. Disponível em: <http://www.cidh.org/ annualrep/80.81sp/EstadosUnidos2141.htm>. Acesso em: 9 fev. 2006.

CHEMERIS, Ivan Ramon. A interrupção da gravidez e o direito. In: A TEORIA e a prática dos saberes cotidianos: Porto Alegre: Ajuris, 2005. p. 101-125.

COOK, Rebecca J. Saúde reprodutiva e direitos humanos: integrando medicina, ética e direito. Rio de Janeiro: Oxford: Cepia, 2004. 
CORRÊA, Sonia; PECHESKY, Rosalind. Direitos sexuais e direitos reprodutivos: uma perspectiva feminista. Physis: Revista de Saúde Coletiva, Rio de Janeiro: IMS: Uerj, v. 6, n. 1/2, p. 147-178, 1996.

CUNHA, Rafael Pagnon. Alvará para interrupção terapêutica de gestação. Sentenças e Decisões de Primeiro Grau: Rio Grande do Sul, Porto Alegre: Ajuris, n. 13, p. 177-186, julho de 2005.

DWORKIN, Ronald. Domínio da vida: aborto, eutanásia e liberdades individuais. São Paulo: Martins Fontes, 2003.

DWYER, Susan. Entendendo o problema do aborto. In: FILOSOFIA Política: nova série, Porto Alegre: L\&PM, 1998. p. 124-150. v. 2.

FONTELES, Cláudio Lemos. Aborto: feto portador de anencefalia. Consulex: Revista Jurídica, São Paulo, v. 8, n. 184, p. 46-49, setembro de 2004.

HARRISON, Beverly Wildung. Nuestro derecho a decidir: hacia una nueva ética del aborto. México: Católicas por el Derecho a Decidir, 2006.

HART, Herbert L. A. Direito, liberdade, moralidade. Porto Alegre: Sergio Antonio Fabris, 1987.

HERVIEU-LÉGER, Danièle. Croire en modernité: au-delà de la problématique dês champs religieux et politiques. In: MICHEL, Patrick (Org.). Religion et démocratie: nouveaux enjeux, nouvelles approches. Paris: Albin Michel, 1997. p. 362-364.

KISSLING, Frances. El Vaticano y las políticas de salud reproductiva. London: Catholics for a Free Choice, 2001.

LEAL, Ondina Fachel; LEWGOY, Bernardo. Aborto: uma contribuição antropológica à discussão. In: FILOSOFIA Política: nova série, Porto Alegre: L\&PM, 1998. p. 173-195. v. 2.

LORDELLO, Josette Magalhães. A secularização do casamento no Brasil do século XIX: entre o Reino de Deus e o Reino dos Homens. Brasília: Editora UnB, 2002. 
LOREA, Roberto Arriada. Violação de direitos. 2005. Disponível em: <http:/ /www.themis.org.br/themis/modules.php?name=News\&file=article\&sid=42>. Acesso em: 9 fev. 2006.

MARTINS, Ives Gandra. Aborto: uma questão constitucional. 2003. Disponível em: <http://www.cienciaefe.org.br/jornal/0312/MT02.htm>. Acesso em: 9 fev. 2006.

MOREIRA, Alexandre Mussoi. Anencefalia e antecipação de parto (a legislação de Buenos Aires). Revista da Ajuris, Porto Alegre, ano 31, n. 95, p. 7-21, set. 2004.

ROSADO-NUNES, Maria José. Aborto, maternidade e a dignidade da vida das mulheres. In: CAVALCANTI, Alcilene; XAVIER, Dulce (Org.). Em defesa da vida: aborto e direitos humanos. São Paulo: Católicas pelo Direito de Decidir, 2006. p. 23-39.

THOMSOM, Judith Jarvis. Uma defesa do aborto. In: FILOSOFIA Política: nova série, Porto Alegre: L\&PM, 1998. p. 106-123. v. 2.

VENTURA, Miriam. Direitos reprodutivos no Brasil. São Paulo: The Hohn D. and Catherine T. MacArthur Foundation, 2002. 